\title{
Terminal Kalibaru sebagai Solusi Mengatasi Kemacetan Bongkar Muat Peti Kemas di Pelabuhan Tanjung Priok Jakarta, 2011-2016
}

\author{
Padliansyah, Endang Susilowati, Sutejo K. Widodo \\ Program Magister Ilmu Sejarah, Fakultas Ilmu Budaya, Universitas Diponegoro
}

Alamat korespondensi: fadlygavet89@gmail.com

\begin{abstract}
This study argues that container loading and unloading congestion at Tanjung Priok Port is caused by long dwelling time due to the limited capacity of existing container terminals. Therefore, the Kalibaru Terminal was built to overcome this problem. The research objective is to look at the planning, construction, and operation of the Kalibaru Terminal. This study uses historical methods consisting of heuristics, source criticism, interpretation, and historiography. The results of this study indicate that the construction of the Kalibaru Terminal is a superior project of government and private cooperation so that it must go through an international tender. The development of Kalibaru Terminal aims to increase productivity and accelerate economic growth. The existence of the Kalibaru Terminal also caused the flow of goods to run smoothly and decrease in dwelling time from eight to three days.
\end{abstract}

Keywords: Container Loading and Unloading; Kalibaru Terminal; Tanjung Priok

Diterima/ Received: 11 Juni 2019

Disetujui / Accepted: 4 Juli 2019
Port; Dwelling Time.

\begin{abstract}
Abstrak
Kajian ini berargumentasi bahwa kemacetan bongkar muat peti kemas di Pelabuhan Tanjung Priok disebabkan dwelling time yang lama akibat keterbatasan daya tampung terminal peti kemas yang ada. Oleh karena itu, Terminal Kalibaru dibangun untuk mengatasi hal tersebut. Tujuan penelitian adalah melihat perencanaan, pembangunan, dan pengoperasionalan Terminal Kalibaru. Kajian ini menggunakan metode sejarah yang terdiri dari heuristik, kritik sumber, interpretasi dan historiografi. Hasil penelitian ini menunjukkan bahwa pembangunan Terminal Kalibaru adalah proyek unggulan kerja sama pemerintah dan swasta sehingga harus melalui tender yang berskala internasional. Pembangunan Terminal Kalibaru bertujuan untuk meningkatkan produktivitas dan mempercepat pertumbuhan ekonomi. Keberadaan Terminal Kalibaru ini juga menyebabkan arus barang semakin lancar dan menurunnya dwelling time dari delapan menjadi tiga hari.
\end{abstract}

Kata Kunci: Bongkar Muat Peti Kemas; Terminal Kalibaru; Pelabuhan Tanjung Priok. 


\section{Pendahuluan}

Latar belakang yang mendasari pembangunan Terminal Kalibaru adalah pesatnya pertumbuhan arus peti kemas pada tahun 1989-2010. Pada tahun 2010 kapasitas Pelabuhan Tanjung Priok semula hanya mampu menampung sebesar 4.800.000 TEU (twenty-foot equvalent unit) dan setelah dilakukan program penataan, perluasan dan rekonfigurasi pelabuhan maka kapasitasnya meningkat menjadi 7.000.000-8.000.000 TEU di tahun 2016. Total realisasi bongkar muat peti kemas di Pelabuhan Tanjung Priok pada tahun 2011 sebesar 5.900.000 TEU per tahun meningkat menjadi 6.200.000 TEU di tahun 2012-2013. Hal ini mengindikasikan perlu segera dilakukan penambahan fasilitas untuk menampung pertumbuhan arus peti kemas di tahuntahun mendatang. Ketika Terminal Kalibaru secara penuh beroperasi pada tahun 2032 mendatang maka Pelabuhan Tanjung Priok diperkirakan mampu menampung sebesar 20.000.000 TEU. Fasilitas Pelabuhan Tanjung Priok hanya mampu melayani kapal dengan kapasitas maksimum 6.000 TEU sedangkan tren pertumbuhan penggunaan kapal peti kemas di dunia saat ini menggunakan kapal dengan kapasitas lebih dari 10.000 TEU dalam rangka mengurangi biaya logistik per TEU sehingga untuk melayani kapal direct call dengan ukuran besar harus disiapkan fasilitas yang memadai (Laporan Tahunan PT Pelabuhan Indonesia, 2014, p. 53).

Pembangunan Terminal Kalibaru merupakan proyek pembangunan pelabuhan terbesar di Indonesia sehingga PT Pelindo II telah memberikan perhatian besar yang mampu memperkuat mata rantai logistik Indonesia secara signifikan serta mengoptimalkan segala upaya demi mewujudkan tujuan proyek ini yaitu untuk meningkatkan kapasitas dan produktivitas jaringan logistik yang lebih optimal sehingga dapat meningkatkan investasi ke Indonesia dan membawa Indonesia menjadi poros maritim dunia. Peletakan batu pertama pembangunan Terminal Kalibaru dilakukan oleh Presiden Ke-6 Republik Indonesia Susilo Bambang Yudhoyono pada tanggal 22 Maret 2013. Pembangunan Terminal Kalibaru terbagi menjadi tiga tahap yakni tahap pertama terdiri atas 3 terminal peti kemas dan 2 terminal produk yang dibangun secara bertahap. Terminal-terminal tersebut direncanakan mulai beroperasi pada tahun 2016, 2023, 2024, 2027 dan 2032. Masingmasing terminal peti kemas didesain untuk kapasitas 1.500.000 TEU. Sementara untuk terminal produk diproyeksikan berkapasitas 10 juta meter kubik per tahun. Pembangunan tahap II meliputi pembangunan empat terminal peti kemas dengan total kapasitas 8.000.000 TEU (Laporan Tahunan PT Pelabuhan Indonesia II, 2015, p. 27). Berdasar pada latar belakang yang telah diuraikan, dirumuskan permasalahan mengenai perencanaan, pembangunan, dan pengoperasian Terminal Kalibaru.

\section{Metode}

Metode yang digunakan dalam penelitian ini adalah metode sejarah yang terdiri dari empat tahap. Tahap pertama adalah heuristik yang merupakan suatu proses untuk mencari dan mengumpulkan sumber-sumber sejarah, baik sumber primer maupun sumber sekunder. Sumber-sumber yang dicari dan dikumpulkan ialah sumbersumber yang relevan dengan tema yang diteliti (Frederick dan Soeroto, 1984, p. 467). 
Setelah sumber dikumpulkan, tahap selanjutnya adalah kritik sumber untuk menentukan otentisitas dan kredibilitas sumber sejarah. Semua sumber yang dikumpulkan terlebih dahulu diverifikasi sebelum digunakan, sebab tidak semua sumber dapat digunakan dalam penulisan. Dua aspek yang dikritik yaitu keaslian sumber dan tingkat kebenaran informasi yang terkandung dalam sumber sejarah. Penentuan keaslian suatu sumber berkaitan dengan bahan yang digunakan untuk membuat sumber tersebut atau dikenal dengan kritik eksteren. Adapun kritik terhadap kredibilitas informasi yang terkandung dalam sumber sejarah dikenal dengan kritik interen. Setiap sumber sejarah diperlakukan sama, yakni diseleksi baik dari segi eksteren maupun interen untuk memperoleh data yang akurat dan valid (Hamid dan Majid, 2011, p. 47-48). Tahap ketiga dalam penelitian sejarah adalah interpretasi. Pada tahap ini dituntut kecermatan dan sikap obyektif, terutama dalam hal interpretasi terhadap fakta sejarah. Hal itu dapat dilakukan dengan mengetahui kondisi umum yang sebenarnya dan menggunakan nalar yang kritis agar dapat disajikan tulisan sejarah yang ilmiah (Hamid dan Majid, p. 47-48). Tahap yang terakhir adalah historiografi, yaitu proses penulisan peristiwa sejarah. Dalam tahap ini faktafakta yang sudah dianalisis dan disintesiskan dipaparkan dalam bentuk tulisan menggunakan bahasa Indonesia yang baik, sehingga mudah dipahami oleh pembaca (Abdullah dan Surjomihardjo, 1985, p. XV).

\section{Perencanaan Pembangunan Terminal Kalibaru}

Pada tahun 2011 operator PT Pelabuhan Indonesia II (Persero) berencana membangun Terminal Kalibaru Tahap 1 dengan kapasitas hingga 4.500.000 TEU di utara Pelabuhan

Tanjung Priok. Fasilitas Pelabuhan Tanjung Priok yaitu pertama, layanan peti kemas di Pelabuhan Tanjung Priok 4.800.000 TEU pada tahun 2010. Kedua, layanan terminal car di Pelabuhan Tanjung Priok untuk 6.000 mobil dengan lahan 12,3 hektar. Ketiga, rancangan pembangunan Terminal Kalibaru berkapasitas 4.500.000 TEU. Keempat, bila tahun 2009 sebanyak 60-65 \% peti kemas asal Pelabuhan Tanjung Priok harus transit di Singapura maka pada tahun 2010 hanya 20 \% (Kompas, 25 Maret 2011).

\section{Proses Tender Terminal Kalibaru Jakarta}

Pada bulan Mei tahun 2011 Terminal Kalibaru telah ditender pemerintah dengan nilai proyek sebesar Rp 8,8 triliun dengan luas 77 hektar dan berkapasitas 4.500.000 TEU. Pembangunan Terminal Kalibaru ini diperuntukan bagi bongkar muat peti kemas dan terminal ini dibangun karena pada tahun 2011 kapasitas peti kemas di Pelabuhan Tanjung Priok tidak memadai. Tender pada Mei 2011 merupakan tender investor. Selain PT Pelindo II belum ada investor yang menyatakan minatnya berinvestasi dalam proyek pemerintah. PT Pelindo II dengan didukung dana dari bank-bank milik pemerintah ini membangun Terminal Kalibaru tetapi harus melalui tender (Kompas, 25 Maret 2011).

Proyek Terminal Kalibaru ternyata diminati oleh perusahaan-perusahaan kelas dunia yang tergabung dalam sejumlah konsorsium. Dengan tambahan kapasitas 4.500.000 TEU maka Pelabuhan Tanjung Priok dapat melayani ekspor-impor. PT 
Pelindo II yang memilih bermitra dalam proyek ini sejak Juli 2011 telah memastikan pembiayaan sebesar US\$1,29 milyar atau setara dengan 11 triliun dari Bank Mandiri. Dukungan pendanaan juga telah didapatkan oleh seluruh peserta kualifikasi misalnya perusahaan pelayaran Jepang Mitsui Lines juga mendapat dukungan dari jaringan perbankan mereka sebesar total kebutuhan investasi (Kompas, 12 Agustus 2011).

Mitsui Lines adalah perusahaan pelayaran kargo yang didirikan pada tahun 1964 dan kini mereka memiliki lebih dari 800 kapal. Bermitra dengan perusahaan pelayaran adalah sebuah keharusan, karena perusahaan-perusahaan tersebut yang menentukan rute kapal atau ship calls secara global. Apalagi Pelabuhan Tanjung Priok menjadi pelabuhan internasional, bukan sekedar pelabuhan pengumpan. Dari daftar peserta kualifikasi Terminal Kalibaru memang muncul nama perusahaan-perusahaan dunia seperti Maersk Line yaitu perusahaan pelayaran yang berkantor pusat di Denmark dan mengoperasikan minimal 500 kapal. Lalu Evergreen Line, perusahaan yang kini mengoperasikan sekitar 180 unit kapal yang dibagi dalam lima kantor operasi. Ada juga Hutchison Port Indonesia yang memegang saham di Jakarta International Container Terminal (JICT) dan Terminal Peti Kemas (TPK) Koja di Pelabuhan Tanjung Priok dan Port Authority of Singapore. Selain itu, juga ada International Container Terminal Services (ICTSI) Filipina juga pernah mengakuisisi terminal peti kemas di Makassar (Kompas, 12 Agustus 2011).

Kementerian Perhubungan (Kemenhub) mengumumkan hasil evaluasi prakualifikasi di proyek Terminal Kalibaru bahwa dua konsursium tidak lulus yakni PT Pelayaran Bintang Putih-A.P.Moller-Maersk Terminal (APM) dan PT Pelabuhan Indonesia IV sedangkan lima perusahaan atau konsorsium lain yang lulus adalah PT Pelindo II, PT Pelabuhan Socah Madura-PSA PE Asia, PT Pelindo I International Container Terminal Services-PT Sinar Rajawali Cemerlang, 4848 Global System-MitsuiEvergreen-Nusantara Infrastruktur, dan PT Hutchison Port Indonesia-PT Brialiant Permata Negara-PT Salam Pacific Indonesia Lines-Cosco Pacific Limited. Hasil evaluasi itu telah diumumkan secara transparan oleh Kementerian Perhubungan dan selanjutnya para konsorsium memasuki tahapan dokumen tender yakni membuat studi kelayakan, rencana pembiayaan, pemasaran, standar operasi dan rencana bisnis. Lima konsorsium itu masih harus bersaing ketat dalam tender untuk memperebutkan proyek Terminal Kalibaru tahap I sebesar Rp 11,70 triliun, di antaranya untuk terminal peti kemas Rp 5,20 triliun, jalan dan jembatan Rp 2,15 triliun, pemecah gelombang $R p$ 1,97 triliun, serta alur Rp 1,07 triliun (Kompas, 12 Agustus 2011).

Proyek Terminal Kalibaru adalah proyek unggulan kerja sama pemerintah dan swasta sehingga proyek ini benar-benar harus dilakukan melalui tender berskala internasional. Total dana pemerintah hanya dapat menutupi 35\% dari keseluruhan biaya yang dibutuhkan, dan sisanya sebesar $65 \%$ harus menggandeng pihak swasta. Bagi pihak swasta, Terminal Kalibaru sangat menarik dengan program pendanaan yang tepat, rencana bisnis dan pemasaran yang baik melalui jaringan dengan shipping line atau perusahaan pelayaran sehingga Terminal Kalibaru ini dapat menguntungkan (Kompas, 12 Agustus 2011). 


\section{Konsesi Terminal Kalibaru Jakarta}

Pada tahun 2011 tingkat pengembalian investasi dari proyek pembangunan Terminal Kalibaru mencapai 14,3\%. Masa konsesi (pemberian hak izin dari pemerintah dan swasta) yang ditawarkan dari 50 tahun hingga 70 tahun. Pemerintah menginginkan ketertarikan investor supaya pelabuhan tersebut lebih cepat terbangun sebab Pelabuhan Tanjung Priok hanya mampu bertahan hingga tahun 2013 karena volume peti kemas yang mampu ditampung hanya mencapai 6.200.000 TEU. Jika membuat perbandingan dengan proyek pelabuhan lain di Asia maka tak terlalu jauh tingkat pengembalian investasinya. Bahkan tingkat pengembalian investasi (internal rate of return on equity/IRR) cukup tinggi. Pra-penjajakan pasar (premarket sounding) telah dilakukan terutama untuk mengetahui animo dan persepsi pasar karena memasukkan nilai investasi jembatan dan alur timur sebagai bagian dari porsi investor (Kompas, 19 Mei 2011).

Pada awalnya Kementerian Perhubungan memberikan kompensasi bagi PT Pelindo II dalam tender Terminal Kalibaru. Kompensasi berupa pemberian tambahan nilai atau pemberian hak untuk menawar atau penawaran terbaik saat tender. Kompensasi tersebut dituangkan dalam Surat Menteri Perhubungan Nomor 4L106/2/14Phb-2011 tanggal, 13 Juni 2011. Kompensasi diberikan ke PT Pelindo II karena statusnya sebagai pemrakarsa pembangunan Terminal Kalibaru. Kompensasi tersebut diatur dalam Pasal 12 dan Pasal 13 Peraturan Presiden Nomor 67 Tahun 2005 tentang Kerja Sama Pemerintah dengan Badan Usaha Dalam Penyediaan Infrastruktur sebagaimana telah diubah dengan Peraturan Presiden Nomor 13 Tahun 2010. Dalam kompensasi tersebut PT Pelindo II diberi hak preferen sebesar 10\%, hak untuk menawar atas penawaran terbaik (right to match) yakni PT Pelindo II dapat menetapkan harga yang sama dengan usul harga terbaik yang diberikan oleh peserta tender lainnya untuk memenangi tender (Kompas, 15 Juni 2011).

Pada 2012 PT Pelindo II secara resmi mendapatkan hak konsesi untuk mengoperasikan Terminal Kalibaru selama 70 tahun sehingga dengan adanya konsesi tersebut maka PT Pelindo II berkewajiban membayar biaya konsesi setiap tahunnya kepada pemerintah sebesar $0,5 \%$ dari pendapatan kotor Terminal Kalibaru sebagai penerimaan negara bukan pajak (PNBP). Dalam perjanjian konsesi antara Otoritas Pelabuhan Tanjung Priok dan PT pelindo II telah disepakati ruang lingkup pembangunan serta pengoperasian Terminal Kalibaru berada di area reklamasi seluas 272 hektare yang terdiri atas dermaga 1A seluas 36 hektare, dermaga 1B seluas 180 hektare dan lokasi pembuangan seluas 56 hektare sehingga di area itu dibangun tiga unit terminal kontainer dan dua unit terminal product dengan kedalaman kolam hingga mencapai 16 m.LWS yang mampu menampung kapal berukuran 150.000 DWT (https://www.viva.co.id/arsip/347928-pelindo-ii-raih-konsesi-70-tahun-terminal-

kalibaru, diakses pada 29 Juni 2019).

\section{Implementasi Pembangunan Terminal Kalibaru}

PT Pelindo II telah mengembangkan strategi jangka panjang untuk merespon peluang menjadi perusahaan pelabuhan internasional di Indonesia. PT Pelindo II saat ini masih 
menjadi pemain utama dalam industri kepelabuhanan dengan kontrol manajemen serta portofolio bisnis yang baik, disertai pertumbuhan perusahaan yang stabil dengan finansial yang sangat baik. Meskipun menghadapi sejumlah tantangan baik dari sisi regulasi, dinamika ekonomi, politik, dan budaya namun PT Pelindo II tetap teguh untuk membangun rencana strategis demi skemajuan perusahaan. Pada tahun 2014 PT Pelindo II telah mengembangkan rencana strategis jangka panjang untuk menjawab tantangan-tantangan tersebut. Di antara rencana dimaksud yaitu membangun Terminal Kalibaru (Laporan Tahunan PT Pelabuhan Indonesia II, 2014, p. 59).

Tabel 1. Rencana Pembangunan Terminal Kalibaru

\begin{tabular}{|c|c|c|c|c|c|c|}
\hline No. & Tahap & Terminal & Jenis & Kapasitas & Kedalaman & Panjang \\
\hline \multirow[t]{10}{*}{1} & \multirow[t]{10}{*}{ Tahap Satu } & Terminal & \multirow[t]{2}{*}{ Container } & 1.500 .000 & $16 \mathrm{~m}-$ & \multirow[t]{2}{*}{$850 \mathrm{~m}$} \\
\hline & & Container 1 & & TEU/tahun & 20m.LWS & \\
\hline & & Terminal & \multirow[t]{2}{*}{ Container } & 1.500 .000 & $16 \mathrm{~m}-$ & \multirow[t]{2}{*}{$800 \mathrm{~m}$} \\
\hline & & Container 2 & & TEU/tahun & 20m.LWS & \\
\hline & & Terminal & \multirow[t]{2}{*}{ Container } & 1.500 .000 & $16 \mathrm{~m}-$ & \multirow[t]{2}{*}{$800 \mathrm{~m}$} \\
\hline & & Container 3 & & TEU/tahun & 20m.LWS & \\
\hline & & Terminal & Produk & $5.000 .000 \mathrm{~m} /$ tahun & $16 \mathrm{~m}-$ & \multirow[t]{2}{*}{$800 \mathrm{~m}$} \\
\hline & & Produk 1 & \multicolumn{2}{|l|}{ Petroleum } & 20m.LWS & \\
\hline & & Terminal & Produk & $5.000 .000 \mathrm{~m} /$ tahun & $16 \mathrm{~m}-$ & \multirow[t]{2}{*}{$800 \mathrm{~m}$} \\
\hline & & Produk 2 & Petroleum & & 20m.LWS & \\
\hline \multirow[t]{2}{*}{2} & \multirow[t]{2}{*}{ Tahap Dua } & Terminal & \multirow[t]{2}{*}{ Container } & 2.000 .000 & $16 \mathrm{~m}-$ & \multirow[t]{2}{*}{$1.000 \mathrm{~m}$} \\
\hline & & Container 4 & & TEU/tahun & 20m.LWS & \\
\hline \multirow[t]{6}{*}{3} & dan & Terminal & \multirow[t]{2}{*}{ Container } & 2.000 .000 & $16 \mathrm{~m}-$ & \multirow[t]{2}{*}{$1.000 \mathrm{~m}$} \\
\hline & Tahap & Container 5 & & TEU/tahun & 20m.LWS & \\
\hline & \multirow[t]{4}{*}{ Tiga } & Terminal & Container & 2.000 .000 & $16 \mathrm{~m}-$ & \multirow[t]{2}{*}{$1.000 \mathrm{~m}$} \\
\hline & & Container 6 & \multirow{3}{*}{ Container } & TEU/tahun & 20m.LWS & \\
\hline & & Terminal & & 2.000 .000 & $16 \mathrm{~m}-$ & \multirow[t]{2}{*}{$1.000 \mathrm{~m}$} \\
\hline & & Container 7 & & TEU/tahun & 20m.LWS & \\
\hline
\end{tabular}

Sumber: PT. Pelabuhan Indonesia II Tahun 2014.

Pembangunan Terminal Kalibaru ini sekaligus merupakan bentuk komitmen PT Pelindo II untuk mendukung kemajuan bangsa Indonesia dan berkontribusi terhadap pertumbuhan nasional atau "committed to progress". Terminal Kalibaru akan menjadi jaringan logistik nasional yang lebih efisien dan lebih mutakhir untuk menarik lebih banyak investasi ke Indonesia. Hal ini dapat meningkatkan produktivitas dibandingkan dengan pelabuhan-pelabuhan besar lainnya di seluruh dunia dan akhirnya mampu memenuhi janji PT Pelindo II untuk meningkatkan perdagangan dan mempercepat pertumbuhan ekonomi Indonesia melalui pengembangan Terminal Kalibaru (Laporan Tahunan PT Pelabuhan Indonesia II, 2014, p. 43).

Terminal Kalibaru juga akan meningkatkan kapasitas dan efisiensi dari jaringan logistik nasional Indonesia dengan produktivitas yang sebanding dengan pelabuhanpelabuhan besar di dunia. Pelabuhan ini juga akan meningkatkan kemampuan dalam 
melayani kapal peti kemas yang lebih besar. Terminal Kalibaru memungkinkan kapal peti kemas kelas Triple E melewati Indonesia tanpa perlu transshipment di pelabuhan lain. Hingga saat ini, kapal Triple E merupakan kelas terbesar dari kapal peti kemas dengan kemampuan membawa hingga 12.000-15.000 TEU (Laporan Tahunan PT Pelabuhan Indonesia II, 2014, p. 44).

Pembangunan Terminal Kalibaru dibagi menjadi tiga tahapan yaitu: jangka pendek (2013-2016), jangka menengah (2017-2023), dan jangka panjang (2023-2032). Namun dalam jurnal ini hanya akan dibahas pembangunan jangka pendek saja, sesuai dengan lingkup temporal, yaitu tahun 2011-2016. Pada tahapan jangka pendek pembangunan Terminal Kalibaru meliputi pembangunan terminal peti kemas yang terdiri dari dermaga peti kemas sepanjang 900 m dengan kedalaman kolam 16 m dan dapat dikembangkan hingga kedalaman $20 \mathrm{~m}$. Terminal peti kemas ini mempunyai luas area 32 ha dengan akses jalan sepanjang $2.803 \mathrm{~m}$. (Departemen Perhubungan Republik Indonesia, 2012, p. 9). Berikut ini adalah konstruksi pembangunan Terminal Kalibaru Tahap I yang terbagi menjadi lima langkah-langkah sebagai berikut: (Laporan Tahunan PT Pelabuhan Indonesia II, 2014, p. 64).

\section{Pekerjaan Pemancangan}

Tiang pancang merupakan struktur pondasi dari proyek pembangunan Container Terminal 1, Terminal Peti Kemas Kalibaru. Total jumlah tiang pancang 12.571 titik yang terbagi dalam 3 varian diameter yakni: diameter $1000 \mathrm{~mm}, 800 \mathrm{~mm}$ dan $500 \mathrm{~mm}$, dengan panjang antara 22-35 $\mathrm{m}$ tanpa sambungan dengan tipe tiang pancang beton (concrete spun pile). Penggunaan sistem tiang pancang (deck on pile) pada konstruksi Container Terminal 1 ini bertujuan untuk menjaga sistem sirkulasi air di sekitar kolam Pelabuhan Tanjung Priok dan kecepatan dalam penyelesaian pembangunan Container Terminal 1. Pekerjaan pemancangan (piling work) sampai akhir tahun 2014 sudah mencapai 9.286 titik untuk Container Yard dan 2.106 titik untuk dermaga 1A yang telah selesai 100\%. Untuk Container Terminal II dan III dilakukan reklamasi perairan di sisi utara Pelabuhan Tajung Priok yang membutuhkan $50.000 .000 \mathrm{~m}^{3}$ material untuk reklamasi yang nantinya digunakan untuk lapangan penumpukan seluas 184 ha dan 2.736 tiang pancang untuk dermaga (jetty).

\section{Pekerjaan Struktur Atas}

Pekerjaan struktur atas dilakukan melalui tiga langkah sebagai berikut; (a) Pekerjaan dermaga 1A yang didesain untuk menampung kapal dengan kapasitas 220.000 DWT. Kolam Dermaga 1A didesain dengan kedalaman sampai $20 \mathrm{~m}$ dan memiliki dimensi $57,5 \mathrm{~m}$ x 850,3 $\mathrm{m}$ dengan struktur deck on pile dan menggunakan beton pracetak (precast concrete). Dermaga 1A sepanjang $450 \mathrm{~m}$ ditargetkan selesai di triwulan III 2015 dan akan selesai secara keseluruhan pada triwulan IV 2015. (b) Container Yard $1 \mathrm{~A}$ merupakan struktur deck on pile dengan sistem operasional area menggunakan crane yang bergerak di atas ban sehingga mobilitasnya tinggi, yang disebut dengan Rubber Tyred Gantry Crane (RTGC). Konstruksi atas Container Yard 1A menggunakan precast concrete yang didirikan di atas tiang-tiang pancang. Target penyelesaian Container Yard 
$1 A$ seluas 16 ha di triwulan III 2015 dan selesai secara keseluruhan pada triwulan IV 2015 dengan total area 32 ha. Sampai dengan akhir Desember 2014 telah terpasang sebanyak 9.286 titik tiang pancang sedangkan untuk pekerjaan atas sampai akhir Desember 2015 sudah mencapai 53,678 $\mathrm{m}^{3}$ concrete in-situ dan 27,285 unit precast concrete terpasang. (c) Pekerjaan Dermaga 1B memiliki desain ukuran kapal yang sama dengan Dermaga 1A dengan kedalaman mencapai $20 \mathrm{~m}$ dan memiliki dimensi 50,0 m x 1658,4 m. Pekerjaan upper structure Jetty 1 A sampai akhir 2014 sudah mencapai 65.097 $\mathrm{m}^{3}$ dan 26.613 beton yang belum terpasang.

\section{Pekerjaan Pengerukan}

Pekerjaan Pengerukan dilakukan untuk mendapatkan kedalaman sesuai dengan rencana yang diinginkan agar dapat dilewati oleh jenis kapal yang direncanakan. Untuk Dermaga 1A dan Dermaga 1B dilakukan pengerukan sampai kedalaman 20.00 $\mathrm{m}$ dengan menggunakan kapal keruk (grab dredger). Kolam Pelabuhan dan Alur Pelayaran dikeruk sampai $16.00 \mathrm{~m}$ menggunakan kapal keruk pemotong dan pengisap (cutter suction dredger). Volume total pengerukan sebesar 25,180,595 $\mathrm{m}^{3}$. Hasil pengerukan akan digunakan sebagai material reklamasi pada tahap 1B.

\section{Pekerjaan Reklamasi Container Yard 1B}

Container Yard 1B miliki dimensi $2.000 \mathrm{~m}$ x $850 \mathrm{~m}$ yang merupakan lahan reklamasi. Area reklamasi adalah area daratan baru yang akan difungsikan sebagai lapangan penumpukan peti kemas di masa yang akan datang dan material reklamasi menggunakan material hasil pengerukan ditambah material pasir. Pasir yang dibutuhkan untuk reklamasi ini adalah sebanyak $9.793 .679 \mathrm{~m}^{3}$ dan pasir untuk reklamasi diangkut menggunakan jenis kapal keruk yang dilengkapi dengan propeller (untuk berlayar) dan ruang muatan material (hopper) atau yang disebut Trailing Suction Hopper Dredger (TSHD) dengan kapasitas $30.000 \mathrm{~m}^{3}$ untuk disebar di area reklamasi. Metode perbaikan tanah menggunakan lembaran plastik untuk drainase vertikal yang panjang dengan berkekuatan mekanik tinggi atau yang disebut Pre-fabricated Vertical Drain (PVD) dan preloading sampai dengan ketinggian 10,5 m. PVD yang digunakan sepanjang $19.162 .680 \mathrm{~m}^{3}$. Pekerjaan pemasangan dinding kanal (silt curtain) telah diselesaikan pada akhir 2014 untuk meminimalkan lumpur akibat reklamasi.

\section{Pekerjaan Pembangunan Breakwater}

Breakwater merupakan pelindung luar area reklamasi dan keseluruhan sistem pelabuhan. Breakwater menggunakan struktur pondasi berupa material bambu (cluster dan matras) dan struktur atas berupa tumpukan batu. Pekerjaan breakwater pada proyek ini membutuhkan 2,1 juta m batu-batuan dengan berbagai berat antara 50-400 $\mathrm{kg}$ dan 5.600 .000 batang bambu yang digunakan untuk matras dan cluster bamboo. Struktur bambu dengan volume 5.600 .000 batang tidak hanya berfungsi sebagai pondasi tetapi juga sebagai struktur penahan gaya lateral terhadap longsor. Ukuran batu yang digunakan bervariasi mulai dari 50-75 kg untuk core, dari $400 \mathrm{~kg}$ untuk cover. Jumlah total batu yang dibutuhkan adalah sebesar 2.182.613 buah. Material baja 
(armor) yang digunakan adalah beton yang dibuat untuk memecahkan ombak atau gelombang dan mengendalikan abrasi yang menggerus garis pantai (jenis $A$-jack) untuk memecah gelombang dari laut lepas.

\section{Peresmian Terminal Kalibaru Tahap I Tahun 2016 \\ Pengoperasian Terminal Kalibaru}

Pada tahun 2016 Presiden Joko Widodo didampingi oleh Menteri Perhubungan Budi Karya Sumadi, Menteri Koordinator Bidang Maritim Luhut B. Pandjaitan, serta Wakil Gubernur DKI Jakarta Djarot Saiful Hidayat meresmikan pengoperasian Terminal Peti Kemas Kalibaru Pelabuhan Utama Tanjung Priok pada Selasa, 13 September 2016. Terminal Kalibaru yang memiliki kapasitas 4.500.000 TEU telah dioperasikan secara komersial pada tanggal 18 Agustus 2016 oleh Join Venture Company, IPC TPK dan Konsorsium Mitsui-PSA-NYK Line.

Pembangunan Terminal Kalibaru didasarkan pada peraturan Presiden RI Nomor 36 Tahun 2012 tentang penugasan kepada PT. Pelindo II untuk membangun dan mengoperasikan Terminal Kalibaru. Peran pelabuhan laut memiliki arti yang sangat penting dalam mobilitas barang dan jasa serta keberadaan pelabuhan yang layak dan modern sangat diperlukan oleh sebuah negara terlebih pada negara maritim seperti Indonesia. Maka pelabuhan bukan hanya sekedar infrastruktur semata melainkan pelabuhan harus juga memiliki keunggulan komplementer yang dikelola dengan baik, profesional serta efisien. Selain itu terkait pentingnya konektivitas yang memadai baik dari prasarana dan sarana transportasi laut guna mendukung pertumbuhan ekonomi nasional (http://dephub.go.id/2017).

Pengoperasian Terminal Kalibaru diharapkan dapat meningkatkan daya saing dalam era kompetisi yang semakin ketat dengan meningkatkan kapasitas dan produktifitas pelabuhan, melakukan modernisasi, penguatan kapasitas dan sinergi yang kuat dengan swasta dan BUMN dengan memanfaatkan pendekatan Public Private Partnership atau Kerjasama Pemerintah dan Swasta (Susantono dan Berawi, 2012, p. 93). Dengan demikian peningkatan efisiensi logistik nasional benar-benar terwujud serta terciptanya kemandirian dalam hal infrastruktur penunjang ekonomi (http://dephub.go.id/2017, diakses 30 Maret 2018).

\section{Uji Coba Terminal Kalibaru Jakarta}

Terminal Kalibaru mulai diuji coba pada Jumat, 27 Mei 2016. Kehadiran Terminal Kalibaru ini dapat menguntungkan semua pihak dan menurunkan biaya logistik. Volume arus peti kemas di Pelabuhan Tanjung Priok hingga tahun 2016 adalah sekitar 7.000.000 TEU setiap tahun. Dengan adanya Terminal Kalibaru maka kapasitas Pelabuhan Tanjung Priok naik dari 7.000.000 TEU per tahun menjadi 11.500.000 TEU per tahun (Kompas, 26 Mei 2016).

Keberadaan Terminal Kalibaru ini menguntungkan pemerintah karena arus barang lancar dan dwelling time (waktu inap barang) juga menurun. Namun bagi PT Pelindo II keuntungan itu belum akan dirasakan sekarang mengingat peti kemas Terminal Kalibaru masih sama saja. Investasi infrastruktur memang membutuhkan 
waktu lama untuk balik modal (Anita dan Asmadewa, 2017, p. 74). Oleh karena itu pemerintah memberi konsesi 70 tahun kepada PT Pelindo II untuk mengelola Terminal Kalibaru ini. Keberadaan Terminal Kalibaru ini juga akan sangat membantu pelayaran karena kapal tak perlu menunggu lama untuk antre masuk ke pelabuhan sehingga lebih efesiensi. Keberadaan Terminal Kalibaru juga menekan biaya logistik yang mencapai 30\% (Kompas, 26 Mei 2016).

Terminal Kalibaru yang lebih modern dan efesien akan membuat proses pemeriksaan barang lebih cepat. Selain itu barang ekspor-impor tidak perlu singgah ke Singapura karena kapal-kapal besar sudah bisa langsung menuju ke Terminal Kalibaru yang mempunyai kedalaman laut 14 meter dan masih akan diperdalam hingga 20 meter. Terminal Kalibaru akan memiliki lima terminal yakni terminal peti kemas 1, 2, 3, dan terminal produk 1 dan 2. Sampai tahun 2016 dibangun terminal 1 sedangkan pembangunan empat terminal lainnya menyusul. Untuk tahap II pembangunan baru diizinkan pemerintah jika utilisasi tahap I mencapai $70 \%$. Terminal Kalibaru memiliki luas sekitar 32 hektar dan memiliki kapasitas 4.500.000 TEU, dilengkapi dermaga sepanjang 850 meter sehingga bisa menampung dua kapal mother vessel dan satu kapal feeder (pengumpan). Dermaga ini bisa melayani kapal peti kemas berkapasitas 13.000-15.000 TEU dengan bobot di atas 150.000 DWT (Kompas, 26 Mei 2016).

Terminal Kalibaru melakukan uji coba pertama dengan melayani Kapal MV Selat Mas dengan GRT 14.000 ton dilaksanakan pada tahun 2016 untuk pelayaran domestik yang mampu membongkar 500 boks peti kemas sedangkan pada uji coba yang kedua melalui Kapal Sinar Sumba dengan GRT 18 ribu ton sandar di Terminal Kalibaru dan melaksanakan kegiatan bongkar 398 boks impor dan 385 boks ekspor. Terminal Kalibaru sudah dipasang peralatan bongkar muat quay container crane sebanyak 8 buah dengan tipe super post-panamax crane dengan produktivitas $27 \mathrm{~s} / \mathrm{d} 30$ boks/crane/jam dan rubber tyred gantry crane (RTGC) telah terpasang sebanyak 20 unit, 60 unit mobil truk dan 2 unit penanganan peti kemas kosong. Terminal ini juga dilengkapi dengan Information Communication Technology (ICT) dengan Cosmos System. ICT yang diterapkan di terminal ini merupakan ICT yang tercanggih dan termodern pada saat itu (https://www.npct1.co.id/introduction, diakses pada 30 Maret 2018).

Terminal Kalibaru diproyeksikan untuk dapat melayani kapal peti kemas dengan kapasitas 13.000-15.000 TEU dengan bobot di atas 150.000 DWT. Terminal ini dioperasikan oleh salah satu perusahaan IPC Group yaitu New Priok Container Terminal One (NPCT1). NPCT1 merupakan terminal peti kemas pertama dalam pembangunan tahap 1 Terminal Kalibaru yang terdiri atas tiga terminal peti kemas dan dua terminal produk. Pembangunan tahap 2 Terminal Kalibaru akan dilaksanakan setelah pengoperasian tahap 1 Terminal Kalibaru. Ketika proyek Terminal Kalibaru telah selesai akan ada total tujuh terminal peti kemas dan dua terminal produk dengan area pendukungnya yang memiliki total area 411 hektare (https://www.npct1.co.id/introduction, diakses pada 30 Maret 2018). 


\section{Manfaat Pembangunan Terminal Kalibaru}

Adapun manfaat dari pengoperasian Terminal Kalibaru berdasar Laporan Tahunan PT Pelabuhan Indonesia II adalah sebagai berikut. (1) Peningkatan kapasitas Pelabuhan Tanjung Priok yang semula 7.000.000-8.000.000 TEU per tahun menjadi 12.000.000 TEU per tahun (tahap I tahun 2016) sehingga dapat menghindari risiko kongesti akibat pertumbuhan peti kemas di pelabuhan yang tinggi; (2) Pelabuhan Tanjung Priok mampu melayani kapal-kapal di atas 10.000-15.000 TEU dengan draft 16 m.LWS di terminal. Terminal ini akan memberikan pelayanan cepat dan tepat dengan fasilitas modern sehingga akan menjadi "Port of Choice" (pelabuhan pilihan) bagi kapal liner internasional dan regional dan pada akhirnya terminal akan menjadi hub port di Indonesia; (3) Tersedianya dedicated terminal untuk product terminal (oil and gas) dengan kapasitas 10.000.000 kubik meter dan terminal ini sekaligus dapat dijadikan sebagai "buffer stock" nasional untuk persediaan minyak bumi dan gas untuk wilayah barat Indonesia; (4) Tercipta lapangan pekerjaan selama pembangunan maupun setelah terminal dioperasikan, tidak hanya di dalam operasi pelabuhan tetapi juga di seluruh sektor kepelabuhanan dan yang berhubungan dengan jaringan distribusi logistik barang; (5) Peningkatan aktivitas dan operasional pelabuhan yang diimbangi dengan produktivitas dan standar pelayanan internasional yang berdampak pada peningkatan penghematan biaya operasional kepelabuhanan dan penghematan nilai waktu (value of time); (6) Peningkatan nilai lahan (land value) hasil reklamasi dan di sekitar koridor pelabuhan dan memberikan citra positif bagi kegiatan operasional di Pelabuhan Tanjung Priok, karena adanya akses jalan yang memadai antara pelabuhan dengan kawasan industri karena Terminal Kalibaru diproyeksikan untuk lebih mampu memenuhi kebutuhan dan keinginan pelanggan di masa mendatang.

\section{Simpulan}

Pada akhir 2011 Pelabuhan Tanjung Priok telah mampu menampung peti kemas sebesar 5.930.000 TEU sedangkan kapasitasnya hanya sebesar 5.000.000 TEU akibat dari peningkatan peti kemas tersebut pemerintah telah menyurvei tujuh lokasi calon pelabuhan atau terminal pendukung Pelabuhan Tanjung Priok yang diprediksi jenuh pada tahun 2013 dan salah satu di antaranya yaitu Kalibaru. Pembangunan Terminal Kalibaru Tahap I dilakukan dengan mereklamasi laut yang dimulai dari breakwater di Pelabuhan Tanjung Priok. Pembangunan terminal tersebut sebagai upaya pemerintah mengantisipasi perkembangan Pelabuhan Tanjung Priok yang setiap tahun semakin padat melayani kedatangan kapal dan muatan dengan berbagai jenis barang yang termasuk barang dalam peti kemas hingga mencapai 6.500.000 TEU pada tahun 2016. Sebelum Terminal Kalibaru beroperasi, Direktorat Jenderal Perhubungan Laut, melalui Unit Pelaksana Teknis (UPT), Kantor Otoritas Pelabuhan Tanjung Priok mendorong pihak operator pelabuhan agar mengoptimalkan kapasitas lahan dan meningkatkan kinerja layanan di pelabuhan dengan cara membuat lahan penumpukan peti kemas baru di dalam pelabuhan dan menetapkan tarif pinalti pada peti kemas impor yang sudah mendapatkan Surat Penyelesaian Pembongkaran 
Barang (SP2B) dari Bea Cukai. Dengan begitu Pelabuhan Tanjung Priok mampu melayani peti kemas yang lebih besar dan menghindari stagnan. Dasar pembangunan Terminal Kalibaru adalah hasil kajian dari Japan International Cooperation Agency (JICA) dan Direktorat Jenderal Perhubungan Laut terkait pengembangan Pelabuhan Tanjung Priok.

\section{Referensi}

Abdullah, T. dan Surjomihardjo, A. (1985). Ilmu Sejarah dan Historiografi: Arah dan Perspektif. Jakarta: PT. Gramedia.

Anita, Sherly L. Asmadewa, I. (2017). Analisis Dwelling Time Impor pada Pelabuhan Tanjung Priok Melalui Penerapan Theory of Constraints. Jurnal Perspektif Bea dan Cukai, 1 (1): 73-87.

Departemen Perhubungan Republik Indonesia, Laporan Rencana Induk PT Pelabuhan Tanjung Priok Provinsi DKI Jakarta, tahun 2012.

Frederick, W. H. S. (1984). Pemahaman Sejarah Indonesia: Sebelum dan Sesudah Reformasi. Jakarta: LP3ES.

Hamid, A. R. dan Majid, M. (2011) Pengantar ilmu sejarah. Yogyakarta: Ombak. http://dephub.go.id/beta2017/post/read/pengoperasian-terminal-kalibarudiharapkan-dapat-meningkatkan-daya-saing-dalam-era-kompetisi-yangsemakin-ketat, (diunduh pada Jumat, 30 Maret 2018, Pukul, 11.00 WIB).

https://www.npct1.co.id/introduction/, diunduh 30 Maret 2018.

https://www.viva.co.id/arsip/347928-pelindo-ii-raih-konsesi-70-tahun-terminal-

kalibaru, diunduh pada Jumat, 30 Maret 2018.

Laporan Tahunan PT Pelabuhan Indonesia II Tahun 2014, 2015.

Susantono, B. dan Berawi, Mohammed A. (2012). Perkembangan kebijakan pembiayaan infrastruktur transportasi berbasis kerjasama pemerintah swasta di Indonesia. Jurnal Transportasi, 12 (2): 93-102.

"Pelabuhan Baru Mendesak Dibangun: Pelabuhan Tanjung Priok Sudah Stagnan", dalam Kompas, Jumat, 25 Maret 2011.

"Pengembangan Tanjung Priok: Lima Konsorsium Lulus di Kalibaru", dalam Kompas, Jumat, 26 Agustus 2011.

“Tender Terminal Kalibaru Dimulai Mei: BUMN Boleh Bersinergi untuk Kalibaru, tetapi Tetap Harus Tender" dalam Kompas, Sabtu, 25 Maret 2011.

"Terminal Kalibaru Diperebutkan: Tujuh Konsorsium Bertarung di Pelabuhan Kalibaru", dalam Kompas, Jumat, 12 Agustus 2011.

“Terminal Kalibaru Diuji Coba: Biaya Logistik Diharapkan Segera Turun” dalam Kompas, Sabtu 26 Mei 2016.

“Terminal Kalibaru Sebagai Magnet Pertumbuhan”, dalam Kompas, Jumat, 1 Februari 2013. 